been added at the end of chapter 11, to explain the phenomenon of saturation in NMR and ESR. Otherwise the second edition stays very close to the first. The opportunity has been taken to remove some minor errors: in particular Fig. 8.6 no longer conveys the impression that band overlap occurs at the zone boundary in one dimension. A remaining source of possible confusion is that while page 124 has "we shall use $\mathrm{e}$ for the modulus of the electronic charge . . . . ", in the section preceding a discussion of the Hall effect we read ". . . . where $\mathrm{e}$ is the electronic charge".

How does Rosenberg's book compare with the dozen or so others which a lecturer might recommend? The author's own list of 'standard texts', with his comments, is as follows:

Solid State Physics. By N.W. Ashcroft and N.D. Mermin. (Holt, Rinehart and Winston:
New York, 1976.) A detailed, higher-level, modern treatment.

Solid State Physics. By J.S. Blakemore. (Saunders: Philadelphia, 1974.) A lively intelligent presentation.

Solid State Physics. By A.J. Dekker. (Macmillan: London, 1960.) A good introductory text.

Introduction to Solid State Physics. By C. Kittel. (Wiley: New York and Chichester, UK, 1976.) A standard text, brim-full with information and data.

Elementary Solid State Physics. By M.A. Omar. (Addison-Wesley: Reading, Massachusetts, 1975.) An introductory text which includes some unusual topics.

Physics of Solids. By C.A. Wert and R.M. Thomson. (McGraw-Hill: New York, 1970.) This is at a lower level than the other texts. It is very well written and illustrated.

Personally I would immediately delete Omar's book from any such list, as it includes a truly astonishing number of errors and misconceptions in its first few chapters, and I would add
Solid State Physics and Its Applications. By R.J. Elliott and A.F. Gibson. (Macmillan; London, 1974.)

Physics students in Edinburgh first meet solid-state physics in an introductory review course of 15 lectures given in the second year. The recommended text book is currently:

Real Solids and Radiation. By A.E. Hughes and D. Pooley. (Wykeham: London, 1975.) A further thirty or so lectures are spread over the third and fourth years of the honours course. When I gave the third year course I recommended Rosenberg and Kittel, in that order, and in the fourth year I reversed the order. So to give the publishers a publishable quote - A book which we shall certainly continue to recommend to students in Edinburgh.

W. Cochran is Professor of Natural Philosophy at the University of Edinburgh, UK.

\section{Animal behaviour in laboratory settings}

\section{Trevor W. Robbins}

The Experimental Analysis of Behaviour. By E. Fantino and C. Logan. Pp.559. (Freeman: Reading, 1979.) $£ 8.40$. Stimulus Control of Behavior. By H.K. Rodewald. Pp.162. (MTP Press: Lancaster; University Park Press: Baltimore, 1979.) $£ 6.25$.

FANTINO and Logan have undertaken the timely but formidable task of writing a student text which attempts to reconcile two often-opposed schools of thought in the study of behaviour: the formulation of general principles from laboratory experiments versus the ethological emphasis upon species-specific behavioural patterns, adaptation to ecological niche and evolution. Generally, they succeed admirably in this well produced and reasonably priced work which takes as its theme the dual ontogenetic and phylogenetic determinants of behaviour.

After a brief historical review of learning theory, basic concepts of operant and Pavlovian conditioning, as well as of "nonassociative" learning such as habituation are described. Chapters on stimulus control, conditioned reinforcement, choice and aversive control then follow, but the rather staid headings belie the fascination of the topics subsumed. These include behavioural contrast, attention, concept formation, behavioural chains, self-control, punishment, self-punitive behaviour and "learned helplessness". There are also welcome allusions to the more successful applications of behaviour therapy such as the "token economy".

From these laboratory concoctions we are delivered quite smoothly across the 'Great Divide' to consider the niceties of courtship in snails and other behaviour in the wild. The ethological section is in many ways symmetric with the previous one, with chapters on species-specific behavioural patterns, "the natural history of learning" and two lengthy surveys of learning in invertebrates. The authors manage to cover taste aversion, specific hungers, imprinting, pigeon-homing, song-learning and the controversies surrounding the famous bee-dance. Considering such breadth, inevitably there are neglected areas. Thus, there is little on motivation, where one might perhaps have expected something on feedback control theory. Similarly, memory and claims of languagelearning in animals are barely mentioned. I should have preferred rather less on learning in Protozoa to Platyhelminthes, where so much of the evidence is indecisive. On the other hand, important advances in the neurophysiology and analysis of learning in Aplysia are well represented.

The book is best suited for advanced students, as few punches are pulled when discussing theoretical issues. For example, the ramifications of Herrnstein's Matching Law are given an extensive quantitative treatment (though Rescorla-Wagner Theory is conveyed with not one equation!). The authors' boldness in incorporating the most recent material into their argument is also impressive, although the drive to synthesis sometimes obscures dissemination. For example, the critique of the use of 'anxiety' as an intervening variable to explain conditioned suppression seems mis-directed when couched physiologically. Neither was I convinced that satiety is "most likely" not a learning phenomenon (page 42), nor by the somewhat glib explanations of "vicious-circle" behaviour.

Minor blemishes are the typographical error which makes nonsense of Equation 7 page 241 , and frustrating references to unpublished talks at meetings, sometimes by one of the authors (for example, page 283)!

However, the book is at its best in the concluding integrative section when the obvious merits of applying 'laboratory' techniques to ethological problems are made clear with examples taken from optimal foraging and displacement or adjunctive behaviour. Finally, the authors examine the "challenge to reinforcement theory". The challenge, with this book, seems well met.

Rodewald's book Stimulus Control of Behavior provides a striking contrast. Here is an unambitious tome which really does justify its perhaps puzzling description as a textbook for undergraduates or a "reference handbook for professionals who will find here a source of useful technology for the study of animal behaviour in laboratory settings". The subject-matter is probably of limited appeal, but is developed in easy steps in the classical pedagogical manner. The book is perhaps most suitable for advanced tuition in practical classes of operant conditioning involving experiments in psychophysics, attention, discrimination or memory. In his book, Rodewald cites some 159 references whereas the corresponding chapter of Fantino and Logan uses 133. It is perhaps of interest that these totals share only 14 references in common. Does compromise between schools of behaviour jeopardise concordance within them?

Trevor W. Robbins is a Lecturer in Experimental Psychology at the University of Cambridge, UK. 